\title{
Overexpression of eis without a mutation in promoter region of amikacin- and kanamycin-resistant Mycobacterium tuberculosis clinical strain
}

\author{
Angkanang Sowajassatakul ${ }^{1}$, Therdsak Prammananan ${ }^{2}$, Angkana Chaiprasert ${ }^{3}$ and Saranya Phunpruch ${ }^{1,4^{*}}$
}

\begin{abstract}
Background: Aminoglycosides such as amikacin and kanamycin are effective injectable second-line drugs for treatment of multidrug-resistant tuberculosis. Molecular mechanisms underlying aminoglycoside resistance are not well understood. We have previously identified the amikacin- and kanamycin-resistant M. tuberculosis MT433 clinical strain, of which all known mutations related to resistance have not been found. Drug efflux pump is one of reported resistance mechanisms that might play a role in aminoglycoside resistance.
\end{abstract}

Methods: The expression levels of sixteen putative efflux pump genes, including eis and one regulator gene, whiB7, of MT433 in the presence of kanamycin were determined using the reverse transcription-quantitative PCR method. The effects of upregulated genes on amikacin and kanamycin resistance were investigated by overexpression in $M$. tuberculosis H37Ra strain.

Results: Upon kanamycin exposure, other than whiB7 and eis that were found extremely overexpressed, two drug efflux pump genes, namely Rv1877 and Rv2846c, showed specifically high-level of expression in M. tuberculosis MT433 strain. However, direct effect of overexpressed Rv1877 and Rv2846C on amikacin and kanamycin resistance could not be demonstrated in M. tuberculosis H37Ra overexpressed strain.

Conclusions: Our finding demonstrated that overexpression of eis could occur without any mutations in the promoter region and be detectable in clinical isolate. This might be a consequence of overexpressed whiB7, resulting in amikacin and kanamycin resistance in M. tuberculosis MT433 strain.

Keywords: Tuberculosis, Drug resistance, Aminoglycoside, Efflux pump, eis, whiB7

\section{Background}

Tuberculosis (TB) is a critical problem for public health in human worldwide. There are approximately 10.4 million global incidence cases of TB in 2016 (140 cases per 100,000 population) and most TB cases have been found in South-East Asian region (about 45\%) [1]. Thailand is estimated as one of the top 20 high TB and TB/ HIV burden countries between year 2016-2020. There

\footnotetext{
${ }^{*}$ Correspondence: saranya.ph@kmitl.ac.th

${ }^{1}$ Department of Biology, Faculty of Science, King Mongkut's Institute

of Technology Ladkrabang, Bangkok 10520, Thailand

Full list of author information is available at the end of the article
}

are approximately $172 \mathrm{~TB}$ incidence cases per 100,000 population in Thailand in 2016 [1]. The emergence of drug resistance tuberculosis remains a significant cause of morbidity and mortality that leads to global problems including treatment and control of TB in many countries. Multidrug-resistant TB (MDR-TB) is defined as TB resistant to at least two most effective first-line antituberculosis drugs (isoniazid and rifampicin) and extensively drug-resistant TB (XDR-TB) is defined as MDR-TB additionally resistant to any fluoroquinolones and one of injectable second-line drugs (amikacin, kanamycin or capreomycin) [2]. In Thailand, approximately 
6.8 MDR-TB incidence cases per 100,000 population were found in 2016 [1].

Amikacin (AMK) and kanamycin (KM) are aminoglycoside drugs generally used to treat MDR-TB [3]. The drugs bind to bacterial $16 \mathrm{~S}$ rRNA in $30 \mathrm{~S}$ ribosomal small subunit, resulting in an inhibition of protein synthesis $[3,4]$. Three known resistance mechanisms of these drugs have been reported in M. tuberculosis. The major resistance mechanism is the modification of drug binding site at adenine base in position 1401 of $\mathrm{rrs}$ gene $[5,6]$. The second mechanism is up-regulation of eis (enhanced intracellular survival), aminoglycosides modifying enzymes (acetyltransferases) encoding gene, that has been shown to confer a low-level kanamycin resistance [7]. The last mechanism is an overexpression of efflux pump genes that leads to a low-level resistance of antibiotics such as isoniazid, fluoroquinolones and aminoglycosides, in Mycobacterium smegmatis and Mycobacterium tuberculosis [8-12].

Efflux pump is a transmembrane protein, which is capable of export antibiotics and toxic compounds out of the cells [13]. There are at least five known families of drug efflux pump in bacteria including major facilitator superfamily (MFS), ATP binding cassette (ABC) transporter family, multidrug and toxic compound extrusion (MATE) family, small multidrug resistance (SMR) family and resistance-nodulation-division (RND) superfamily [14, 15]. In $M$. tuberculosis, the energy metabolism and ATP production from proton motive force (PMF) determine the drug susceptibility [16]. Tap (encoding by Rv1258c), the putative efflux pump, has been shown to play a role in aminoglycoside resistance in M. tuberculosis [17, 18].

Our previous study revealed that AMK- and KMresistant M. tuberculosis clinical strains, MT433 and MT164, showed high-level resistance to AMK and $\mathrm{KM}(\mathrm{MIC}>64 \mu \mathrm{g} / \mathrm{ml})$. None of point mutations in all known resistant genes, including $r r s$, eis promoter region, tap, and whiB7, has been reported in M. tuberculosis MT433 strain whereas A1401G mutation of rrs gene has been found in M. tuberculosis MT164 strain [19]. It is possible that expression level of genes, particularly genes encoding drug efflux pump, might play a significant role in the resistant phenotype of this MT433 strain. The present study, therefore, aimed to investigate the expression levels of 16 genes encoding putative efflux pumps and hypothetical predicted transmembrane proteins, eis and also whiB7, in $M$. tuberculosis MT433 and MT164 using the reverse transcription-quantitative PCR (RT-qPCR) method. Effects of overexpressed genes on AMK and KM susceptibility were validated in M. tuberculosis H37Ra strain.

\section{Methods}

Mycobacterial strains and culture conditions

Amikacin- and kanamycin-resistant M. tuberculosis MT433 and M. tuberculosis MT164 strains were obtained from the Drug-Resistant Tuberculosis Research Fund, Siriraj Foundation, Faculty of Medicine Siriraj Hospital, Mahidol University, Bangkok, Thailand. The M. tuberculosis MT433 was isolated from sputum of a male patient, 26 years of age who got a treatment at Maharaj Nakhon Ratchasima hospital, Nakhon Ratchasima province, Thailand. Draft genome sequence of M. tuberculosis MT433 was analyzed and submitted to the NCBI under Accession No. LGAX00000000 [20]. M. tuberculosis MT164 was previously characterized and found to carry the mutation in the rrs A1401G gene [19]. Mycobacteria were cultured on LöwensteinJensen (LJ) medium (BBL, USA) [21] and cultures were incubated at $37^{\circ} \mathrm{C}$ for $3-4$ weeks.

\section{Isolation of total RNA}

One loopful of M. tuberculosis MT433 and MT164 cells were suspended in $500 \mu \mathrm{l}$ of $10 \mathrm{mM}$ Tris- $\mathrm{HCl}$ buffer containing $1 \mathrm{mM}$ EDTA ( $\mathrm{pH}$ 8.0). Cells were harvested by centrifugation at $12,000 \times g$ for $2 \mathrm{~min}$. Cell pellet was resuspended in $1 \mathrm{ml}$ of Middlebrook 7H9 medium [22] containing $6 \mu \mathrm{g} / \mathrm{ml}$ of $\mathrm{KM}$. The cell mixture was incubated at $37^{\circ} \mathrm{C}$ for $1 \mathrm{~h}$ before harvesting cells by centrifugation. Total RNA was isolated using TRIzol reagent (Invitrogen, USA) [23]. One millilitre of TRIzol reagent was added into the cell pellet. The mixture was mixed by vortexing for $15 \mathrm{~s}$ and then incubated on ice for $15 \mathrm{~s}$. This procedure was done three times. Subsequently, total RNA was purified using PureLink ${ }^{\circledR}$ RNA Mini Kit (Ambion, USA). The residual DNA in RNA was removed by adding DNaseI (Invitrogen, USA) with a final concentration of $0.05 \mathrm{U} / \mu \mathrm{l}$. The mixture was incubated at $37{ }^{\circ} \mathrm{C}$ for $1 \mathrm{~h}$. The concentration of total RNA was determined by measuring an absorbance at $260 \mathrm{~nm}$ using NanoDrop ${ }^{\text {TM }}$ 2000/2000c Spectrophotometer (Thermo Fisher Scientific, USA).

\section{Complementary DNA (cDNA) synthesis}

The cDNA synthesis was performed using the RevertAid First Strand cDNA Synthesis Kit (Thermo Fisher Scientific, USA). RNA was reverse-transcribed in $20 \mu \mathrm{l}$ reaction mixture containing Transcriptor reverse transcriptase buffer (50 mM Tris- $\mathrm{HCl}(\mathrm{pH} 8.3), 50 \mathrm{mM}$ $\mathrm{KCl}, 4 \mathrm{mM} \mathrm{MgCl}_{2}$ and $\left.10 \mathrm{mM} \mathrm{DTT}\right), 10 \mathrm{U}$ of protector RNase Inhibitor (Promega, USA), $0.25 \mathrm{mM}$ each dNTP (Invitrogen, USA), $2 \mu \mathrm{M}$ RT primer (Additional file 1: Table S1), $1 \mu \mathrm{g}$ of RNA and $10 \mathrm{U}$ of Transcriptor reverse transcriptase (Thermo Fisher Scientific, USA). 
The RT-PCR reaction mixture was incubated at $42{ }^{\circ} \mathrm{C}$ for $30 \mathrm{~min}$ and reaction was stopped by incubating at $85^{\circ} \mathrm{C}$ for $5 \mathrm{~min}$.

\section{Determination of genes expression using reverse transcription quantitative real-time PCR (RT-qPCR)}

The RT-qPCR reaction was performed by PrimeScript ${ }^{\mathrm{TM}}$ RT Master Mix (Takara, USA) using PikoReal ${ }^{\mathrm{TM}}$ 24-well Real-time PCR System (Thermo Fisher Scientific, USA) according to the manufacturer's protocol. The $\operatorname{sig} A$ gene encoding the major sigma factor of RNA polymerase that is constitutively expressed in M. tuberculosis [24] was used as a reference gene for normalization of gene expression in this study. Briefly, $20 \mu \mathrm{l}$ of reaction mixture comprised PrimeScript RT Master Mix (10 mM Tris$\mathrm{HCl}$ (pH 8.3), $15 \mathrm{mM} \mathrm{KCl}, 1.6 \mathrm{mM} \mathrm{MgCl}_{2}$ ) containing $2 \mathrm{mM}$ each dNTP $10 \mu \mathrm{M}$ each primer (Additional file 1: Table S1), $0.2 \mu \mathrm{g}$ of cDNA and $4 \mathrm{U}$ of PrimeScript Reverse Transcriptase (Takara, Japan). The qPCR condition consisted of an initial denaturation at $95{ }^{\circ} \mathrm{C}$ for $5 \mathrm{~min}$, followed by 45 cycles of amplification with denaturation at $95{ }^{\circ} \mathrm{C}$ for $20 \mathrm{~s}$, annealing at $60^{\circ} \mathrm{C}$ for $30 \mathrm{~s}$ and extension at $72{ }^{\circ} \mathrm{C}$ for $20 \mathrm{~s}$. The $2^{-\Delta \Delta \mathrm{Cq}}$ calculation method was used for the relative quantification of gene expression as previously described $(\mathrm{Cq}$ is the quantification cycle or the cycle number at which a threshold amount of amplicon DNA is produced) [25]. The $\Delta \mathrm{Cq}$ is the cycle difference between $\mathrm{Cq}$ of target gene and $\mathrm{Cq}$ of reference gene $(\operatorname{sig} A)$ (control) $(\Delta \mathrm{Cq}=\mathrm{Cq}$ target gene $-\mathrm{Cq}$ reference gene). The $\Delta \Delta \mathrm{Cq}$ is the cycle difference between $\Delta \mathrm{Cq}$ of sample (KM exposed cells) and $\Delta \mathrm{Cq}$ of calibrator (KM unexposed cells $)(\Delta \Delta \mathrm{Cq}=\Delta \mathrm{Cq}$ sample $-\Delta \mathrm{Cq}$ calibrator $)$. The $2^{-\Delta \Delta C q}$ value is a relative quantification of gene expression. When compared relative gene expressions of target genes in cells with and without KM exposure conditions, expression level above 1 was considered as "increased expression" and expression level equal to or above 4 was considered as "overexpression" [25-28].

\section{Construction of Rv1877 and Rv2846c overexpressed in $M$. tuberculosis H37Ra strains}

Rv1877 and Rv2846c genes were amplified by PCR using specific primers (Forward Rv1877-BamHI 5'-GGATCC ATGGCGGGCCCCA-3' and Reverse Rv1877-BamHI 5'-GGATCCCTACGTTGTAGCCGCGA-3' for Rv1877 amplification and Forward Rv2846c-BamHI 5'-GGA TCCATGACGGCTCTCAACGACAC-3' and Reverse Rv2846c-BamHI 5'-GGATCCTTACAGCTCGCCGGC GTCGA-3' for Rv2846c amplification). PCR was conducted in $50 \mu$ l reaction mixture containing $20 \mathrm{mM}$ Tris- $\mathrm{HCl}$ (pH 8.4), $50 \mathrm{mM} \mathrm{KCl,} 1.5 \mathrm{mM} \mathrm{MgCl}_{2}, 200 \mu \mathrm{M}$ each dNTP, $0.5 \mu \mathrm{M}$ each primer, $50 \mathrm{ng}$ of genomic DNA and 2.5 U of Taq DNA polymerase (Promega, USA). The
PCR condition consisted of an initial denaturation at $94{ }^{\circ} \mathrm{C}$ for $5 \mathrm{~min}$, followed by 35 cycles of denaturation at $94{ }^{\circ} \mathrm{C}$ for $30 \mathrm{~s}$, annealing at $60{ }^{\circ} \mathrm{C}$ for $1-2 \mathrm{~min}$ and extension at $72{ }^{\circ} \mathrm{C}$ for $7 \mathrm{~min}$. PCR products were purified using QIAquick PCR Purification Kit (Qiagen, Germany). The amplified products were submitted to DNA sequencing for confirming the accuracy of nucleotide sequences and directions. The amplified genes were then subcloned into the plasmid pSMT1, which is a replicative plasmid carrying a hygromycin resistance cassette [29], by replacing the $\operatorname{lu} x A B$ gene in sense and antisense directions, resulting in the recombinant plasmids pSMT1-Rv1877(S), pSMT1-Rv1877(AS), pSMT1-Rv2846c(S), and pSMT1Rv2846c(AS). The recombinant plasmids were transformed into M. tuberculosis H37Ra by electroporation. Briefly, M. tuberculosis H37Ra competent cells were prepared by culturing bacteria until $\mathrm{OD}_{600}$ reached approximately 0.75 . Cells were harvested by centrifugation at $5000 \times g$ for $10 \mathrm{~min}$ at $4{ }^{\circ} \mathrm{C}$ and washed three times with ice-chilled $10 \%$ glycerol before centrifugation again. The cell pellet was finally resuspended in 1/100 original culture volume of ice-chilled $10 \%$ glycerol. One $\mu \mathrm{g}$ of recombinant plasmid DNA was added into $100 \mu \mathrm{l}$ of competent cells. DNA was introduced into the competent cells by electroporation using Gene Pulser (Bio-Rad, USA) with a pulse controller setting at voltage $2.5 \mathrm{kV}$, capacitor 25 $\mu \mathrm{F}$ and resistance $1000 \Omega$. Positive transformants were selected on Middlebrook 7H10 agar containing 10\% Oleic acid-albumin-dextrose-catalase (OADC) and $50 \mu \mathrm{g} / \mathrm{ml}$ of hygromycin.

\section{Drug susceptibility testing and determination of minimal inhibitory concentration (MICs)}

The susceptibility testing was performed by agar dilution method on Middlebrook 7H10 agar (Difco, USA) supplemented with $10 \%$ OADC [30]. The MICs value of AMK and $\mathrm{KM}$ were determined on agar containing $50 \mu \mathrm{g} / \mathrm{ml}$ of hygromycin and a single concentration of each drug ( 0 , 4, 8, and $16 \mu \mathrm{g} / \mathrm{ml}$ ) (Sigma Aldrich, Germany). The MICs were defined as the lowest concentration of AMK and KM that prevented visible growth of mycobacteria after incubation for $3-4$ weeks at $37^{\circ} \mathrm{C}$.

\section{Results \\ Expression levels of efflux pump genes upon kanamycin exposure in M. tuberculosis MT433 and MT164}

The expression levels of 16 efflux pump and hypothetical transmembrane protein encoding genes, aminoglycoside acetyltransferase (eis) gene, and transcription regulator whiB7 were determined in M. tuberculosis MT433 (KM-resistant strain with unknown mechanism) and M. tuberculosis MT164 (KM-resistant strain with rrs A1401G mutation) after exposure to $6 \mu \mathrm{g} / \mathrm{ml}$ of $\mathrm{KM}$ by 
RT-qPCR. The expressions of all target genes upon KM exposure were compared with those of reference gene and those of unexposed controls. Results revealed that KM could induce expression of several genes with different manners (Table 1 and Fig. 1). Three genes (Rv1877, Rv2846c, and Rv2416c) were specifically upregulated in M. tuberculosis MT433 upon KM exposure but they were downregulated or slightly increased in $M$. tuberculosis MT164 strain. In addition, four genes (Rv0783c, Rv1250, Rv2333c, and Rv1145) were specifically upregulated in M. tuberculosis MT164 upon KM exposure but these genes were downregulated in another strain. Three genes (Rv1634, Rv1457c and Rv1458c) showed a downregulation in both strains. Interestingly, eis (Rv2416c) was found significantly overexpressed only in M. tuberculosis MT433 whereas tap (Rv1258c) was much higher overexpressed in MT164 strain than MT433 strain. The transcriptional regulator whiB7 (Rv3197A) involving in aminoglycoside resistance was extremely up-regulated in both strains.

\section{Construction of overexpressed M. tuberculosis H37Ra strains}

In order to determine whether the significantly high upregulated efflux pump encoding genes, Rv1877 and Rv2846c, could directly affect the AMK and KM

Table 1 Differential expression of genes investigated upon kanamycin exposure in $M$. tuberculosis MT433 and MT164 strains

\begin{tabular}{|c|c|c|}
\hline \multirow[t]{2}{*}{ Genes } & \multicolumn{2}{|c|}{$\begin{array}{l}\text { Differential expression fold } \\
\text { change }\left(2^{-\Delta \Delta C q}\right)\end{array}$} \\
\hline & MT433 & MT164 \\
\hline Rv0194 & 0.9 & 1.0 \\
\hline Rv0783c & 0.1 & 24.7 \\
\hline Rv1145 & 0.2 & 195.0 \\
\hline Rv1146 & 1.3 & 4.2 \\
\hline Rv1250 & 0.3 & 1.3 \\
\hline Rv1258c (tap) & 6.0 & $4.0 \times 10^{7}$ \\
\hline Rv1410c & 2.0 & 3.6 \\
\hline Rv1456c & 1.0 & 1.0 \\
\hline Rv1457c & 0.0 & 0.0 \\
\hline Rv1458c & 0.8 & 0.7 \\
\hline Rv1634 & 0.7 & 0.5 \\
\hline Rv1819c & 2.6 & 1.9 \\
\hline Rv1877 & 22.8 & 1.0 \\
\hline Rv2333c & 0.7 & 1.1 \\
\hline Rv2416c (eis) & $2.2 \times 10^{3}$ & 0.9 \\
\hline Rv2846c & 1.6 & 0.6 \\
\hline Rv3065 & 1.2 & 2.7 \\
\hline Rv3197A (whiB7) & $2.0 \times 10^{7}$ & $7.0 \times 10^{6}$ \\
\hline
\end{tabular}

susceptibility, recombinant plasmids pSMT1 carrying each Rv1877 and Rv2846c with different directions, sense (S) and antisense (AS), were constructed and transformed into M. tuberculosis H37Ra. Four or eight transformants of each overexpressed M. tuberculosis H37Ra strains, namely H37Ra::Rv1877(S), H37Ra::Rv1877(AS), H37Ra::Rv2846c(S), and H37Ra::Rv2846c(AS) were selected for further investigation. The susceptibility of AMK and KM was investigated in all overexpressed strains, including M. tuberculosis H37Ra::pSMT1 control strain.

\section{Susceptibility of overexpressed M. tuberculosis H37Ra strains to amikacin and kanamycin}

The minimal inhibitory concentrations (MIC) of AMK and $\mathrm{KM}$ were determined in all overexpressed strains. Results revealed that neither overexpressed M. tuberculosis H37Ra strains carrying Rv1877 nor Rv2846c could confer either AMK or KM resistance as summarized in Table 2.

\section{Discussion}

In this study, the expression levels of 16 efflux pump genes, eis, and whiB7 were investigated upon kanamycin exposure in M. tuberculosis MT433 (resistant strain with unknown mechanism) and the resistant control $M$. tuberculosis MT164 (strain with rrs A1401G mutation), and the effect of overexpressed genes on AMK and KM susceptibility was determined by performing the gene overexpression experiments in M. tuberculosis H37Ra strain. Previous study reported that overexpression of eis resulting from mutations located at the promoter region is the second most common cause of KM resistance [7]. Eis is a mycobacterial effector that is related to the survival within human macrophage [31,32] and suppression of eis made the anaerobic persistent bacilli susceptible to the aminoglycoside antibiotics [33]. In addition, the enhanced eis expression due to the specific mutations in promoter region which exhibited a low-level KM resistance in KM-resistant $M$. tuberculosis clinical isolates [7, 34, 35]. Similarly, high expression level of eis (Rv2416c) has been detected in our study (Table 1 and Fig. 1), suggesting that eis might be related to phenotypic KM resistance in $M$. tuberculosis MT433 even if this strain did not contain any mutations in the promoter region [19]. Concordantly, the whiB7 (Rv3197A) was also found significantly overexpressed in this strain and even in the resistant strain with $r r s$ mutation (Table 1 and Fig. 1). WhiB7, an inducible putative transcriptional regulator, has been shown to regulate several genes including eis and tap; both are involved in aminoglycoside resistance [36, 37]. Our results indicated that overexpression of whiB7 resulted in significant overexpression of eis only in the MT433 strain but not in MT146 strain, suggesting that overexpression of eis is not necessary in case of strain carrying $r r s$ mutation. However, the mechanism underlying 

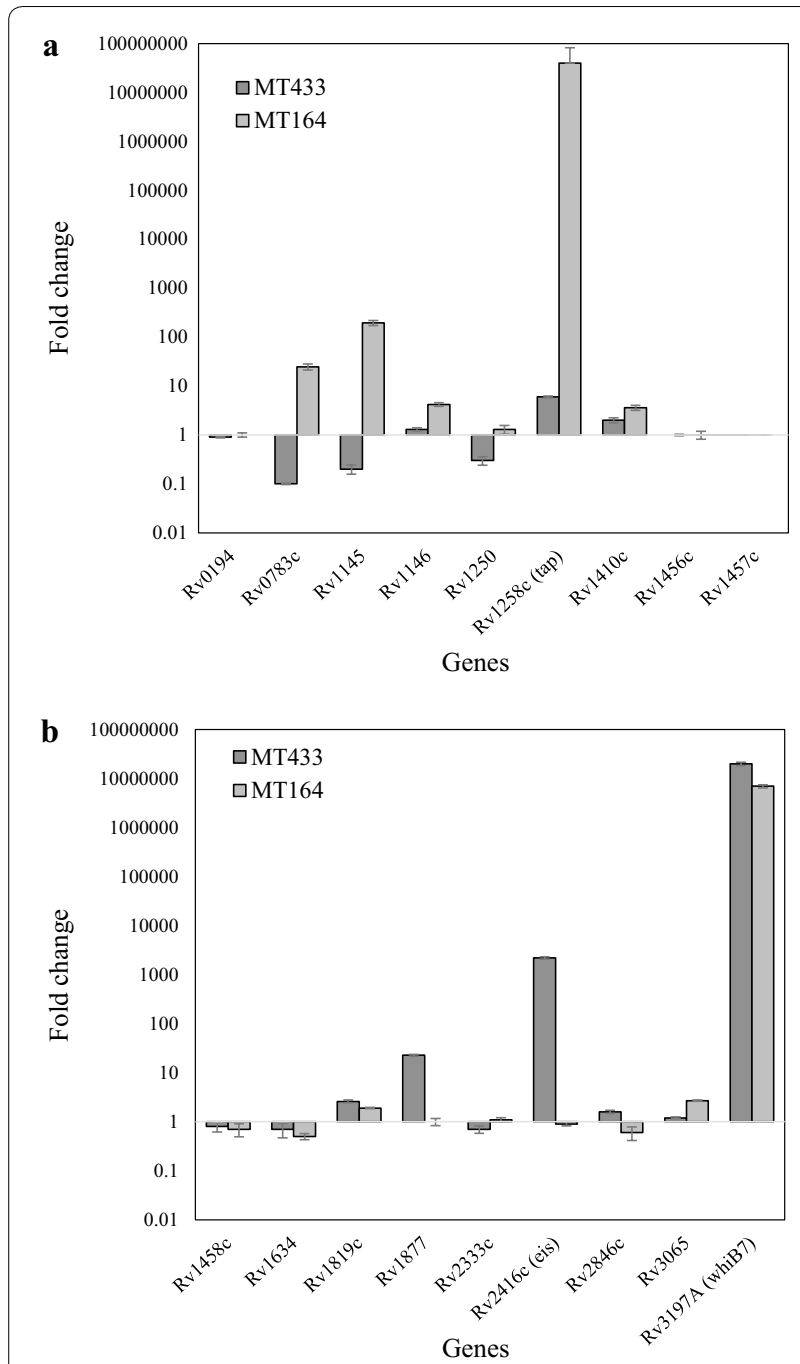

Fig. 1 The relative fold change of the expression levels of genes, Rv0194, Rv0783c, Rv1 145, Rv1146, Rv1250, Rv1258c (tap), Rv1410c, Rv1456c, Rv1457c (a), Rv1458c, Rv1634, Rv1819c, Rv1877, Rv2333c, Rv2416 (eis), Rv2846c, Rv3065 and Rv3197A (whiB7) (b) in kanamycin-resistant M. tuberculosis MT433

Table 2 MICs of amikacin and kanamycin of overexpressed M. tuberculosis H37Ra strains

\begin{tabular}{lll}
\hline Strains & \multicolumn{2}{l}{ MIC $(\boldsymbol{\mu g} / \mathbf{m l})$} \\
\cline { 2 - 3 } & Amikacin & Kanamycin \\
\hline H37Ra & 4 & 4 \\
H37Ra:::pSMT1 & 4 & 4 \\
H37Ra::Rv1877(S) & 4 & 4 \\
H37Ra::Rv1877(AS) & 4 & 4 \\
H37Ra::Rv2846C(S) & 4 & 4 \\
H37Ra::Rv2846C(AS) & 4 & 4 \\
\hline
\end{tabular}

high overexpression of whiB7 and eis without any mutations at promoter region occurred in this MT433 clinical strain remains inconclusive.

Another possibility that might be responsible for drug resistance is the drug efflux mechanism. High-level expression of two specific genes in the major facilitator superfamily (MFS), Rv1877 and Rv2846c (efpA), was found only in the MT433 strain. It is possible that overexpression of these two genes is also involved in AMK and KM resistance. Previous studies described several secondary transporters capable of exporting cation compounds and antibiotics including antituberculosis drugs, such as isoniazid, rifampicin and aminoglycosides [38, 39]. The efflux pump protein Rv0783c, Rv1250, Rv1258c (Tap), Rv1410c (P55), Rv1634, Rv1877, Rv2333c, Rv2846c and Rv3239c were also categorized into the MFS family [33]. Deletion of Rv1877 homologue in M. smegmatis (58\% identity to $M$. tuberculosis Rv1877) increased susceptibility to erythromycin, novobiocin, tetracycline, and KM [40]. Our findings did not show any direct evidences suggesting that Rv1877 is related to AMK and KM resistance because overexpression of this gene in $M$. tuberculosis H37Ra could not increase the MICs against AMK and KM (Table 2). Previous study showed that deletion of efpA (Rv2846c) homologue has been shown to increase susceptibility to ethidium bromide and acriflavine but it decreased susceptibility to rifampicin, isoniazid and chloramphenicol in M. smegmatis [24]. No evidence has been reported for this gene in $M$. tuberculosis. However, overexpression of Rv2846c (efpA) did not confer AMK and KM resistance (Table 2). Results indicated that both Rv1877 and Rv2846c did not directly affect the susceptibility of the MT433 strain to AMK and KM. The remaining genes, excepting for Rv1258c and Rv1410c that were found overexpressed in both MT433 and MT164 strains, were found down-regulated in the MT433 strain.

On the other hand, four specific genes, Rv0783c (emrB), Rv1145, Rv1250, and Rv2333c (stp), were significantly upregulated in the MT164 strain that contains A1401G mutation in rrs whereas seven genes, namely Rv1146, Rv1258c (tap), Rv1410c, Rv1456c, Rv1819c (bacA), Rv3065 (mmr) and Rv3197A (whiB7), were found overexpressed in both strains (Table 1 and Fig. 1). Rv1145 and Rv1146 are classified into the resistance-nodulationdivision (RND) family that showed $62 \%$ homologous to $m m p L$ of $M$. smegmatis [40]. Although their nucleotide sequences showed homologous to the $M$. smegmatis $m m p L$ efflux pump gene, they did not function as a drug efflux pump in M. tuberculosis [40]. Rv1456c, Rv1457c and Rv1458c, the ATP-binding cassette (ABC) superfamily genes, have been found overexpressed in the presence 
of ethambutol, isoniazid, rifampicin, and streptomycin in M. tuberculosis [41]. Rv2333c has been reported to associate with aminoglycoside resistance in $M$. tuberculosis clinical isolates [42]. However, it is unclear whether in a strain harboring a well-characterized mutation conferring resistance, like MT164, the increasing expression level of efflux pump genes still plays a role in the resistant phenotype.

\section{Conclusions}

In this study, the high expression level of eis was found in M. tuberculosis MT433 whereas the downregulation of eis was found in M. tuberculosis MT164. An unusual resistance mechanism was firstly described, by which overexpression of eis without any mutations in the promoter region was identified by the reverse transcription quantitative real-time PCR. It should be considered that any resistant $M$. tuberculosis strains caused by this mechanism could not be detected by all currently available diagnostic tests for detection of drug resistance. Our finding provides a new insight that could benefit for developing a new test with higher sensitivity. In addition, several drug efflux genes were found selectively overexpressed in the presence of drug either in strains with or without a known mutation conferring resistance. However, the exact role of these efflux genes could not be demonstrated in the present study.

\section{Additional file}

Additional file 1: Table S1. Primers used in this study.

\section{Authors' contributions}

AS performed all experiments in this study and drafted the manuscript. AS, TP, AC and SP analyzed the results and formatted the data. TP and SP conceptualized and designed the experimental procedures, supervised all the experimental works, corrected and produced the final version of the manuscript. AC provided clinical MTB strains, supervised the microbiological experiments and produced the final version of the manuscript. All authors read and approved the final manuscript.

\section{Author details}

${ }_{1}^{1}$ Department of Biology, Faculty of Science, King Mongkut's Institute of Technology Ladkrabang, Bangkok 10520, Thailand. ${ }^{2}$ Tuberculosis Research Laboratory, National Center for Genetic Engineering and Biotechnology, National Science and Technology Development Agency, Pathum Thani 12120, Thailand. ${ }^{3}$ Research Affairs, Faculty of Medicine Siriraj Hospital, Mahidol University, Bangkok 10700, Thailand. ${ }^{4}$ Bioenergy Research Unit, Faculty of Science, King Mongkut's Institute of Technology Ladkrabang, Bangkok 10520, Thailand.

\section{Acknowledgements}

A. Sowajassatakul is thankful for a scholarship for the Ph.D. program that was provided by the Thailand Graduate Institute of Science and Technology (TGIST), National Science and Technology Development Agency (NSTDA). We would also like to acknowledge Ms. Sarinya Jaitrong and Ms. Nampueng Makhao for their excellent technical assistance.

\section{Competing interests}

The authors declare that they have no competing interests.

\section{Ethics approval and consent to participate}

This study was approved by the Siriraj Ethics Committee, Mahidol University, Bangkok, Thailand (Certificate of Approval No. Si 208/2005).

\section{Funding}

This study was financially supported by the Faculty of Science, King Mongkut's Institute of Technology Ladkrabang (KMITL) (2559-01-05-078) and the DrugResistant Tuberculosis Research Fund under the Patronage to Her Royal Highness Princess Galayani Vadhana Krom Luang Naradhiwas Rajanagarindra, Siriraj Foundation, Faculty of Medicine Siriraj Hospital, Mahidol University.

\section{Publisher's Note}

Springer Nature remains neutral with regard to jurisdictional claims in published maps and institutional affiliations.

Received: 6 April 2018 Accepted: 9 July 2018

Published online: 16 July 2018

\section{References}

1. WHO 2017. Global tuberculosis report 2017. WHO report. 2017. http:// apps.who.int/iris/bitstream/handle/10665/259366/9789241565516en g.pd? sequence $=1 ; 1-262$. Accessed 1 Dec 2017.

2. WHO. 2010. Global report on surveillance and response: multidrug and extensively drug-resistant TB (M/XDR-TB). WHO report. 2010. http:// apps.who.int/iris/bitstream/handle/10665/44286/9789241599191_eng. pdf;jsessionid=D6F89400546D72016946A53E51BFD712? sequence $=1$. Accessed 1 Dec 2010.

3. Hermann T. Aminoglycoside antibiotics: old drugs and new therapeutic approaches. Cell Mol Life Sci. 2007;64(14):1841-52.

4. Recht MI, Douthwaite S, Puglisi JD. Basis for prokaryotic specificity of action of aminoglycoside antibiotics. EMBO J. 1999;18(11):3133-8.

5. Suzuki Y, Katsukawa C, Tamaru A, Abe C, Makino M, Mizuguchi Y, Taniguchi H. Detection of kanamycin-resistant Mycobacterium tuberculosis by identifying mutations in the 165 rRNA gene. J Clin Microbiol. 1998;36(5):1220-5

6. Narang A, Giri A, Gupta S, Garima K, Bose M, Verma-Basil M. Contribution of putative efflux pump genes to isoniazid resistance in clinical isolates of Mycobacterium tuberculosis. Int J Mycobacteriol. 2017;6(2):177-83.

7. Zaunbrecher MA, Sikes RD, Metchock B, ShinickTM, Posey JE. Overexpression of the chromosomally encoded aminoglycoside acetyltransferase eis confers kanamycin resistance in Mycobacterium tuberculosis. Proc Natl Acad Sci USA. 2009;106(47):20004-9.

8. Liu J, Takiff HE, Nikaido H. Active efflux of fluoroquinolone in Mycobacterium smegmatis mediated by LfrA, a multidrug efflux pump. J Bacteriol. 1996;178(13):3791-5.

9. Takiff HE, Cimino M, Musso MC, Weisbrod T, Martinez R, Delgado MB, Salazar L, Bloom BR, Jacobs WR. Efflux pump of the proton antiporter family confers low-level fluoroquinolone resistance in Mycobacterium smegmatis. Proc Natl Acad Sci USA. 1996;93(1):362-6.

10. Wang K, Pei H, Huang B, Zhu X, Zhang J, Zhou B, Zhu L, Zhang Y, Zhou FF. The expression of ABC efflux pump, Rv1217c-Rv1218c, and its association with multidrug resistance of Mycobacterium tuberculosis in China. Curr Microbiol. 2013;66(3):222-6.

11. Blair JM, Webber MA, Baylay AJ, Ogbolu DO, Piddock LJ. Molecular mechanisms of antibiotic resistance. Nat Rev Microbiol. 2015;13(1):42-51.

12. Li G, Zhang J, Guo Q, Jiang Y, Wei J, Zhao L, Zhao X, Lu J, Wan K. Efflux pump gene expression in multidrug-resistant Mycobacterium tuberculosis clinical isolates. PLoS ONE. 2015;10(2):e0119013.

13. Louw GE, Warren RM, van Gey Pittius NC, McEvoy CR, Helden PD, Victor TC. A balancing act: efflux/influx in mycobacterial drug resistance. Antimicrob Agents Chemother. 2009;53(8):3181-9.

14. De Rossi E, Arrigo P, Bellinzoni M, Silva PAE, Martin C, Aínsa JA, Guglierame $P$, Riccardi G. The multidrug transporters belonging to major facilitator superfamily in Mycobacterium tuberculosis. Mol Med. 2002;8(11):714-24. 
15. Sarathy JP, Dartois V, Lee EJD. The role of transport mechanisms in Mycobacterium tuberculosis drug resistance and tolerance. Pharmaceuticals. 2012;5(11):1210-35.

16. Black PA, Warren RM, Louw GE, Van Helden PD, Victor TC, Kana BD. Energy metabolism and drug efflux in Mycobacterium tuberculosis. Antimicrob Agents Chemother. 2014;58(5):2491-503.

17. Morris RP, Nguyen L, Gatfield J, Visconti K, Nguyen K, Schnappinger D, Ehrt S, Liu Y, Heifets L, Pieters J, Schoolinik G, Thompson CJ. Ancestral antibiotic resistance in Mycobacterium tuberculosis. Proc Natl Acad Sci USA. 2005;102(34):12200-5.

18. Aínsa JA, Blokpoel MCJ, Otal I, Young DB, De Smet KAL, Martin C. Molecular cloning and characterization of Tap, a putative multidrug efflux pump present in Mycobacterium fortuitum and Mycobacterium tuberculosis. J Bacteriol. 1998;180(22):5836-43.

19. Sowajassatakul A, Prammananan T, Chaiprasert A, Phunpruch S. Molecular characterization of amikacin, kanamycin and capreomycin resistance in M/XDR-TB strains isolated in Thailand. BMC Microbiol. 2014;14:165.

20. Sowajassatakul S, Coker OO, Prammananan T, Chaiprasert A, Phunpruch S. Draft genome sequence of amikacin- and kanamycin-resistanct Mycobacterium tuberculosis MT433 without rrs and eis mutations. Genome Announc. 2015;3(6):e01363-415.

21. Der Lowenstein E. kulturelle Nacheweis von Tuberkelbakterien in Milch auf Malachitgrun Einahrboden. Ann Inst Pasteur. 1933;50:161.

22. Atlas RM. Handbook of microbiological media. 4th ed. Florida: CRC Press; 2006

23. Rio DC, Ares M Jr, Hannon GJ, Nilsen TW. Purification of RNA using TRIzol (TRI reagent). Cold Spring Harb Protoc. 2010. https://doi.org/10.1101/ pdb.prot5439.

24. Rodrigue S, Provvedi R, Jacques PÉ, Gaudreau L, Manganelli R. The sigma factors of Mycobacterium tuberculosis. FEMS Microbiol Rev. 2006;30(6):926-41.

25. Livak KJ, Schmittgen TD. Analysis of relative gene expression data using real-time quantitative $P C R$ and the $2(-\triangle \triangle C(T))$ method. Methods. 2001;25(4):402-8.

26. DeMarco CE, Cushing LA, Frempong-Manso E, Seo SM, Jaravaza TA, Kaatz GW. Efflux-related resistance to norfloxacin, dyes, and biocides in bloodstream isolates of Staphylococcus aureus. Antimicrob Agents Chemother 2007;51(9):3235-9.

27. Rodrigues L, Machado D, Couto I, Amaral L, Viveiros M. Contribution of efflux activity to isoniazid resistance in the Mycobacterium tuberculosis complex. Infect Genet Evol. 2012;12(4):695-700.

28. Bustin SA, Beaulieu JF, Huggett J, Jaggi R, Kibenge FS, Olsvik PA, Penning LC, Toegel S. MIQE précis: practical implementation of minimum standard guidelines for fluorescence-based quantitative real-time PCR experiments. BMC Mol Biol. 2010;11:74

29. Snewin VA, Gares MP, Gaora PÓ, Hasan Z, Brown IN, Young DB. Assessment of immunity to mycobacterial infection with luciferase reporter constructs. Infect Immun. 1999;67(9):4586-93.
30. NCCLS. M24-A2. Susceptibility testing of Mycobacteria, Nocardiae, and other aerobic actinomycetes; approve standard. 2nd ed. Wayne: National Committee for Clinical Laboratory Strandards; 2003.

31. Wei J, Dahl JL, Moulder JW, Roberts EA, O'Gaora P, Young DB, Friedman $\mathrm{RL}$. Identification of a Mycobacterium tuberculosis gene that enhances mycobacterial survival in macrophages. J Bacteriol. 2000;182(2):377-84.

32. Pan $\mathrm{Q}$, Zho FL, Ye BC. Eis, a novel family of arylalkylamine $\mathrm{N}$-acetyltransferase. Sci Rep. 2018;8:2435.

33. Maurya VK, Singh K, Sinha S. Suppression of Eis and expression of Wag31 and GroES in Mycobacterium tuberculosis cytosol under anaerobic culture conditions. Indian J Exp Biol. 2014;52(8):773-80.

34. Chen W, Biswas T, Porter VR, Tsodikov OV, Garneau-Tsodikova S. Unusual regioversatility of acetyltransferase Eis, a cause of drug resistance in XDRTB. Proc Natl Acad Sci USA. 2011;108(24):9804-8.

35. Kambi P, Ajbani K, Nikam C, Sadani M, Shetty A, Udwadia Z, Georghiou SB, Rodwell TC, Catanzaro A, Rodriques C. Correlation rrs and eis promoter mutations in clinical isolates of Mycobacterium tuberculosis with phenotypic susceptibility levels to the second line injectables. Int J Mycobacteriol. 2016;5(1):1-6.

36. Reeves AZ, Campbell PJ, Sultana R, Malik S, Murray M, Plikaytis BB, Shinnick TM, Posey JE. Aminoglycoside cross-resistance in Mycobacterium tuberculosis due to mutations in the $5^{\prime}$ untranslated region of whiB7. Antimicrob Agents Chemother. 2013;57(4):1857-65.

37. Pryjma M, Burian J, Kuchinski K, Thompson CJ. Antagonism between front-line antibiotics clarithromycin and amikacin in the treatment of Mycobacterium abscessus infections is mediated by the whiB7 gene. Antimicrob Agents Chemother. 2017;61(11):e01353-417.

38. Putman M, Van Veen HW, Konings WN. Molecular properties of bacteria multidrug transporters. Microbiol Mol Biol Rev. 2000;64(4):672-93.

39. Machado D, Perdigão J, Portugal I, Pieroni M, Silva PA, Couto I, Viveiros M. Efflux activity differentially modulates the levels of isoniazid and rifampicin resistance among multidrug resistant and monoresistant Mycobacterium tuberculosis strains. Antibiotics. 2018;7(1):18.

40. Li XZ, Zhang L, Nikaido H. Efflux pump-mediated intrinsic drug resistance in Mycobacterium smegmatis. Antimicrob Agents Chemother. 2004:48(7):2415-23.

41. Hao P, Shi-Liang Z, Ju L, Ya-Xin D, Biao H, Xu W, Min-Tao H, Shou-Gang K, Ke W. The role of ABC efflux pump, Rv1456-Rv1457c-Rv1458c, from Mycobacterium tuberculosis clinical isolates in China. Folia Microbiol. 2011;56(6):549-53.

42. Jiang X, Zhang Y, Gao F, Lu C, Zhang X, Wang H. Assessment of efflux pump gene expression in a clinical isolate Mycobacterium tuberculosis by real-time reverse transcription PCR. Microb Drug Resist. 2008;14(1):7-11.
Ready to submit your research? Choose BMC and benefit from:

- fast, convenient online submission

- thorough peer review by experienced researchers in your field

- rapid publication on acceptance

- support for research data, including large and complex data types

- gold Open Access which fosters wider collaboration and increased citations

- maximum visibility for your research: over 100M website views per year

At $\mathrm{BMC}$, research is always in progress.

Learn more biomedcentral.com/submissions 